\title{
Frequent occurrence of nicotinic acetylcholine receptors in GABAergic neurons of the chick visual system
} A.S. Torrão and
L.R.G. Britto

\author{
Departamento de Fisiologia e Biofísica, Instituto de Ciências Biomédicas,
} Universidade de São Paulo, São Paulo, SP, Brasil

\section{Correspondence \\ A.S. Torrão \\ Departamento de Fisiologia e \\ Biofísica, ICB, USP \\ Av. Prof. Lineu Prestes, 1524 \\ 05508-900 São Paulo, SP \\ Brasil \\ Fax: + 55-11-3818-7426 \\ E-mail: andrea@fisio.icb.usp.br \\ Research supported by FAPESP, CNPq and PRO NEX/MCT. A.S. Torrão was the recipient of a postdoctoral fellowship from FAPESP.}

Received April 4, 2001

Accepted August 2, 2001

\section{Abstract}

Double-labeling immunohistochemical methods were used to investigate the occurrence of the $\alpha 8$ and $\alpha 5$ nicotinic receptor subunits in presumptive GABAergic neurons of the chick nervous system. Nicotinic receptor immunoreactivity was often found in cells exhibiting GABA-like immunoreactivity, especially in the visual system. The $\alpha 8$ subunit appeared to be present in presumptive GABAergic cells of the ventral lateral geniculate nucleus, nucleus of the basal optic root of the accessory optic system, and the optic tectum, among several other structures. The $\alpha 5$ subunit was also found in GABA-positive neurons, as observed in the lentiform nucleus of the mesencephalon and other pretectal nuclei. The numbers of $\alpha 8$ - and $\alpha 5$-positive neurons that were also GABA-positive represented high percentages of the total number of neurons containing nicotinic receptor labeling in several brain areas, which indicates that most of the $\alpha 8$ and $\alpha 5$ nicotinic receptor subunits are present in GABAergic cells. Taken together with data from other studies, our results indicate an important role of the nicotinic acetylcholine receptors in the functional organization of GABAergic circuits in the visual system.

\author{
Key words \\ - Acetylcholine \\ - GABA \\ - Neurotransmitters \\ - Nicotinic receptors \\ - Visual system
}

Nicotinic acetylcholine receptors (nAChRs) have been reported to be widely distributed in the central nervous system $(1,2)$, where most of them appear to have a modulatory role (3-5). Indeed, several studies have shown a predominance of presynaptic nAChRs in the visual $(1,6,7)$ and other neural systems (5). In addition, several electrophysiological and pharmacological data are suggestive of a modulatory function of nAChRs upon dopaminergic, glutamatergic, noradrenergic (4), and GABAergic (8-14) circuits. As part of a program to chemically identify the central neurons containing nAChRs, we investigated the occurrence of
nAChR subunits in presumptive GABAergic neurons of the chick brain by means of double-labeling immunohistochemical techniques. The $\alpha 8$ and $\alpha 5 \mathrm{nAChR}$ subunits were chosen for this analysis, as they represent different $\mathrm{nAChR}$ families (2) and also because monoclonal antibodies $(\mathrm{mAb})$ directed against these two subunits have produced reliable cellular labeling in previous experiments $(1,15)$.

Ten 1-2-week-old chicks (Gallus gallus) were used in the present study. The birds were deeply anesthetized with ketamine and xylazine and perfused through the heart with $0.9 \%$ saline and $2 \%$ paraformaldehyde (PFA) 
in $0.1 \mathrm{M}$ phosphate buffer (PB, $\mathrm{pH}$ 7.4). The brains were postfixed in 2\% PFA for 3-5 h and then transferred to $30 \%$ sucrose in $\mathrm{PB}$ for cryoprotection. Coronal sections $(30 \mu \mathrm{m})$ of the frozen brains were cut with a sliding microtome and submitted to immunohistochemical procedures. The brain sections were processed free-floating according to a doublelabeling protocol, either with a combination of the rat mAb305 against the $\alpha 8 \mathrm{nAChR}$ subunit (16) and a guinea pig antiserum against GABA (Eugenetech, Ridgefield Park, NJ, USA), or with a combination of the rat mAb210 against the $\alpha 5 \mathrm{nAChR}$ subunit $(2,17)$ and the guinea pig antiserum against GABA. All antibodies were diluted 1:250 in PB containing $0.3 \%$ Triton X-100. Sections were initially incubated with the mixture of primary antibodies for 14-18 $\mathrm{h}$ at room temperature (ca. $\left.22^{\circ} \mathrm{C}\right)$. After three washes $(15$ min each) in PB, the sections were incubated for $1 \mathrm{~h}$ at room temperature with a mixture of a goat anti-rat antiserum labeled with rhodamine and a rabbit anti-guinea pig antiserum
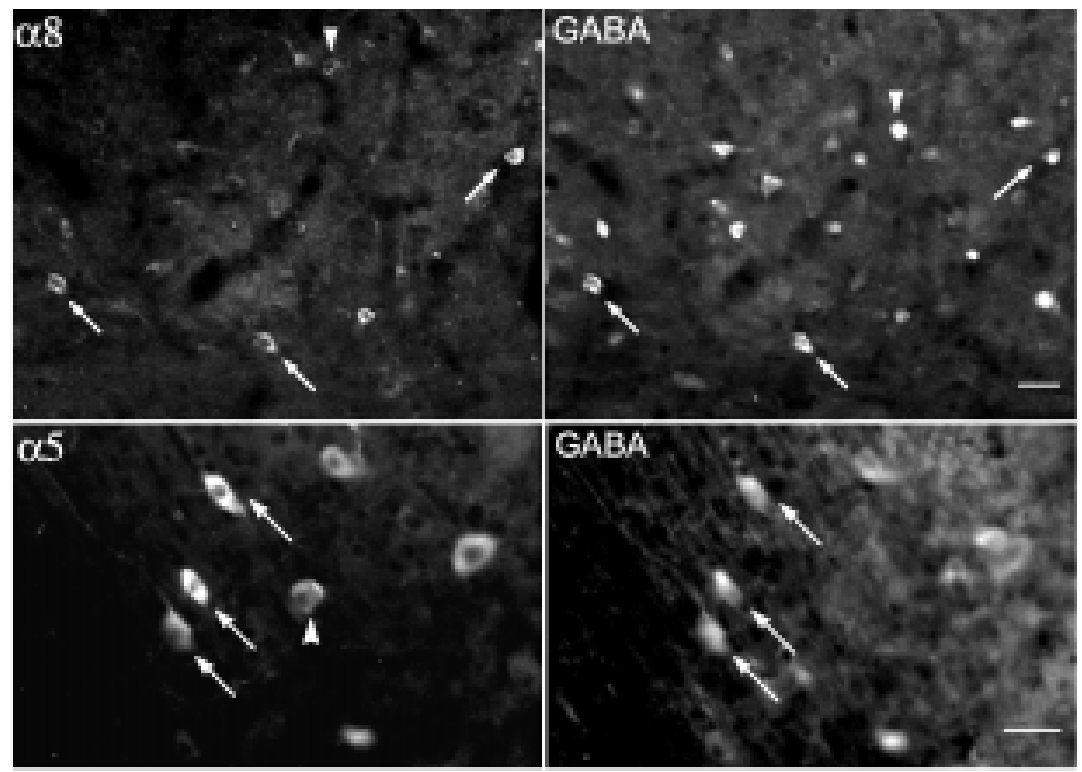

Figure 1. Digital images of coronal sections of the chick brain through the ventral lateral geniculate nucleus (top) and the lentiform nucleus of the mesencephalon (bottom), taken under rhodamine ( $\alpha 8$ and $\alpha 5)$ and fluorescein (GABA) microscope filters. The arrows indicate double-labeled neurons and the arrowheads indicate neurons containing only one of the antigens studied. GABA, gamma-aminobutyric acid. Scale bars: $25 \mu \mathrm{m}$. Note the greater magnification of the bottom images. labeled with fluorescein, both diluted 1:100 in PB. The sections were then washed in PB as described before, mounted on gelatin and chromoalumen-coated slides, and coverslipped with a mixture of carbonate buffer and glycerin. As the antigens studied here are not readily available for preadsorption controls, in some experiments we have omitted the primary antibodies from the procedure or replaced them with normal sera of the same species as the antibodies. Specific staining was completely abolished in both control conditions. The material was analyzed with a fluorescence microscope using the appropriate filters and also with a Zeiss 510 confocal microscope. Double labeling was subjectively evaluated, and cell counts were performed in order to obtain an overall index of co-occurrence of the $\alpha 8$ and $\alpha 5 \mathrm{nAChR}$ subunits with GABA. These cell counts included only the neurons that stained well above the background, and were performed in at least three sections/animal for each of the structures analyzed here.

The GABA-immunostaining pattern found in the present study for the chick brain was similar to that previously described for the pigeon brain (18), and the patterns of $\alpha 8$ and $\alpha 5$ immunoreactivity agreed well with previous descriptions from our laboratory $(1,15)$. As expected, GABA-immunoreactive cells are much more widely distributed in the chick brain than neurons containing the $\alpha 8$ and $\alpha 5$ nAChR subunits. Doublestained cells containing the $\alpha 8$ subunit of the nAChRs and GABA were found in several structures. These cells were especially frequent in visual system structures, such as the ventral lateral geniculate nucleus (Figure 1), nucleus of the basal optic root of the accessory optic system, and the optic tectum. Some structures exhibited an especially high percentage of $\alpha 8$-positive cells which also contained GABA, such as the subpretectal nucleus (approximately 74\%), the ventral lateral geniculate nucleus (about 75\%), and the lentiform nucleus of the mesencephalon 
(ca. 70\%). Several structures also exhibited double labeling for the $\alpha 5 \mathrm{nAChR}$ subunit and GABA, such as the pretectal area, isthmic nucleus, magnocellular portion, and the lentiform nucleus of the mesencephalon(Figure 1). Among the structures that exhibited high percentages of $\alpha 5$-positive cells which also contained GABA are the gray tectal nucleus ( $100 \%$ of the $\alpha 5$-positive cells), the lentiform nucleus of the mesencephalon (approximately $83 \%$ ), the isthmic nucleus, magnocellular portion (about $90 \%$ ), and the lateral spiriform nucleus (ca. 80\%). The approximate percentages of cholinoceptive neurons ( $\alpha 8$ - or $\alpha 5$-positive) that contain GABA in several structures of the chick brain are summarized in Table 1. It should be stressed that co-localization of nAChR subunits and GABA was also marked in some non-visual structures, such as the ventral tegmental area and lateral hypothalamus (high numbers of $\alpha 8 /$ GABA-positive cells), the interpeduncular nucleus (moderate numbers of $\alpha 8$ - and $\alpha 5$-positive neurons containing GABA), and the subpretectal nucleus (high numbers of $\alpha 8 / \mathrm{GABA}$ - and $\alpha 5 / \mathrm{GABA}-$ positive cells). Despite the high number of GABA-positive neurons in the chick brain, we could also subjectively estimate the number of presumptive GABAergic neurons containing $\alpha 8$ or $\alpha 5 \mathrm{nAChR}$ subunits. These numbers were highly variable among structures, ranging from about $5 \%$ in the optic tectum to about $90 \%$ in the lateral spiriform nucleus and the isthmic nucleus, magnocellular portion. The numbers, however, were very consistent among data from different experiments. The degree of consistency of these numbers was as high as the consistency of the approximate numbers given above for the cholinoceptive neurons containing GABA immunoreactivity.

The data of the present study suggest that many neurons of the chick brain containing both $\alpha$-bungarotoxin-sensitive $(\alpha 8)$ and $\alpha$ bungarotoxin-insensitive $(\alpha 5)$ nAChR subunits (2) also contain GABA immunoreac- tivity. This indicates that in several chick brain structures the majority of the cholinoceptive neurons are possibly GABAergic. The numbers of cholinoceptive neurons containing GABA in the chick visual system are possibly even higher than those described above, for at least two reasons. First, the immunofluorescence technique is recognizably less sensitive than other immunohistochemical protocols, which suggests that the approximate numbers of double-labeled (nAChR/GABA) neurons given here could actually be higher. Second, we have only tested two nAChR subunits, and the possibility exists that other subunits are also present in GABA-positive neurons. It should be stressed, however, that $\alpha 5$ must assemble with other nAChR subunits in order to generate functional receptors. It is noteworthy that the distribution of the $\alpha 5 \mathrm{nAChR}$ subunit is similar to the distribution of the $B 2$ subunit in the chick brain $(1,15)$. The $\alpha 8$ subunits can constitute functional homo-oligomeric receptors, but they may also as-

Table 1. Approximate percentages of cholinoceptive neurons which contain GABA in the chick brain.

\begin{tabular}{lcc}
\hline \multirow{2}{*}{ Brain structures } & \multicolumn{2}{c}{ nAChRs + GABA } \\
\cline { 2 - 3 } & $\begin{array}{c}\alpha 8 \text {-positive neurons } \\
\text { with GABA (\%) }\end{array}$ & $\begin{array}{c}\alpha \text {-positive neurons } \\
\text { with GABA (\%) }\end{array}$ \\
\hline Deep mesencephalic nucleus & $*$ & 10 \\
Dorsal thalamus & 40 & $*$ \\
Gray tectal nucleus & $*$ & 100 \\
Interpeduncular nucleus & 39 & 26 \\
Isthmic nucleus, magnocellular portion & $*$ & 90 \\
Lateral hypothalamus & 72 & $*$ \\
Lateral spiriform nucleus & 40 & 80 \\
Medial reticular formation & 35 & $*$ \\
Mesencephalic lentiform nucleus & 70 & $* 3$ \\
Nucleus of the basal optic root & 55 & $*$ \\
Optic tectum & 65 & 48 \\
Pretectal area & 26 & 60 \\
Subpretectal nucleus & 74 & $*$ \\
Ventral lateral geniculate nucleus & 75 & 0 \\
Ventral tegmental area (Tsai) & 42 &
\end{tabular}

*These structures contain very little (or undetectable) $\alpha 8$ or $\alpha 5$ immunoreactivity in perikarya, despite exhibiting GABA-positive cells. nAChRs, nicotinic acetylcholine receptors; GABA, gamma-aminobutyric acid. 
semble with $\alpha 7$ subunits in the avian brain (2). In fact, these two subunits of the $\alpha$ bungarotoxin-sensitive nAChR family cooccur in several visual areas of the chick brain (1).

The frequent occurrence of nAChRs in GABAergic neurons may either represent a morphological substrate for the existence of presynaptic nicotinic receptors which may modulate GABA release, or represent postsynaptic receptors which may directly control the activity of GABAergic cells. The first of these possibilities implies that the existence of nAChR subunits in GABA-positive neurons may mean that these subunits are present in the cell body en route to axon terminals, where they could have a modulatory role (1). In the second case, the staining of perikarya may possibly represent somatic nAChRs, located either on the cell membrane or in the cytoplasm as part of a cytoplasmic receptor pool (2). There are a series of physiological data indicating an effect of nicotinic agonists on the facilitation of GABA release. This effect has been found in the sensory thalamus (11), the rat dorsal motor nucleus of the vagus nerve (9), the hippocampus (8), the ventral lateral geniculate nucleus (10), the lateral spiriform nucleus (14), and cortical interneurons (19). GABAergic axons in these areas should therefore express nicotinic receptors in a terminal or preterminal location, so that these receptors could modulate GABA release. Very little information appears to exist concerning possible postsynaptic effects of nAChRs upon GABAergic neurons. In only one of the structures analyzed here, namely the lateral spiriform nucleus, does a possibility clearly exist of fast postsynaptic nAChRs acting upon GABAergic cells (13). Additional studies are needed to identify the presynaptic or postsynaptic nature of the nAChRs found in GABAergic neurons in this study.

The presence of nAChRs in GABAergic neurons demonstrated here in visual areas of the chick brain does not appear to be limited to that particular neural system. Indeed, the physiological data mentioned above suggest the occurrence of nAChRs in GABAergic neurons in other neural systems and in the brains of other species, including humans $(8-11,14,19)$. Also, the analysis of the extensive maps of the distribution of nAChRs and GABA in the brain of birds and other species (see $1,2,18)$ reveals that the nicotinic receptor-GABA relationship is likely to extend to the majority of brain areas. Further studies are clearly necessary to evaluate the latter possibility. Interestingly, the $\alpha 3 \mathrm{nAChR}$ subunit has already been detected in GABAergic perikarya of the chick retina (20). The numbers of cholinoceptive neurons exhibiting the GABA phenotype and the numbers of GABAergic neurons expressing nAChRs both varied according to the retinal area analyzed, reaching almost $40 \%$ in both cases (20). Taken together with the latter data in the retina, the present results reveal a close relationship of nAChRs and GABA in the chick visual system and add information about a modulatory role of acetylcholine, acting on nAChRs, in GABAergic circuits.

\section{Acknowledgments}

Thanks are due to Dr. Jon M. Lindstrom, University of Pennsylvania, for his kind donation of monoclonal antibodies against nicotinic receptor subunits. 


\section{References}

1. Britto LRG, Keyser KT, Lindstrom J M \& Karten HJ (1992). Immunohistochemical localization of nicotinic acetylcholine receptor subunits in the mesencephalon and diencephalon of the chick (Gallus gallus). J ournal of Comparative Neurology, 317: 325-340.

2. Lindstrom J (1996). Neuronal nicotinic acetylcholine receptors. In: Narahashi T (Editor), Ion Channels. Plenum Press, New York, 377-450.

3. MacDermott AB, Role LW \& Siegelbaum AS (1999). Presynaptic ionotropic receptors and the control of transmitter release. Annual Review of Neuroscience, 22: 443485.

4. Vizi ES \& Lendvai B (1999). Modulatory role of presynaptic nicotinic receptors in synaptic and non-synaptic chemical communication in the central nervous system. Brain Research Reviews, 30: 219-235.

5. Wonnacott S (1997). Presynaptic nicotinic ACh receptors. Trends in Neurosciences, 20: 92-98.

6. Sargent PB, Pike SH, Nadel DB \& Lindstrom J M (1989). Nicotinic acetylcholine receptor-like molecules in the retina, retinotectal pathway, and optic tectum of the frog. J ournal of Neuroscience, 9: 565573.

7. Swanson LW, Simmons DM, Whiting PJ \& Lindstrom J (1987). Immunohistochemical localization of neuronal nicotinic receptors in the rodent central nervous system. J ournal of Neuroscience, 7: 33343342.

8. Alkondon M, Pereira EFR, Barbosa CTF \&
Albuquerque EX (1997). Neuronal nicotinic receptor activation modulates gammaaminobutyric acid release from CAl neurons of rat hippocampal slices. J ournal of Pharmacology and Experimental Therapeutics, 283: 1396-1411.

9. Bertolino M, Kellar KJ , Vicini S \& Gillis RA (1997). Nicotinic receptor mediates spontaneous GABA release in the rat dorsal motor nucleus of the vagus. Neuroscience, 79: 671-681.

10. Guo J Z, Tredway TL \& Chiappinelli VA (1998). Glutamate and GABA release are enhanced by different subtypes of presynaptic nicotinic receptors in the lateral geniculate nucleus. J ournal of Neuroscience, 18: 1963-1969.

11. Léna C \& Changeux JP (1997). Role of $\mathrm{Ca}^{2+}$ ions in nicotinic facilitation of GABA release in mouse thalamus. J ournal of Neuroscience, 17: 576-585.

12. Lu Y, Grady S, Marks MJ, Picciotto M, Changeux J P \& Collins AC (1998). Pharmacological characterization of nicotinic receptor-stimulated GABA release from mouse brain synaptosomes. J ournal of Pharmacology and Experimental Therapeutics, 287: 648-657.

13. Nong $Y$, Sorenson EM \& Chiappinelli VA (1999). Fast excitatory nicotinic transmission in the chick lateral spiriform nucleus. J ournal of Neuroscience, 19: 7804-7811.

14. Zhu PJ \& Chiappinelli VA (1999). Nicotine modulates evoked GABAergic transmission in the brain. J ournal of Neurophysiology, 82: 3041-3045.

15. Torrão AS, Lindstrom J M \& Britto LRG
(1997). Distribution of the $\alpha 2, \alpha 3$, and $\alpha 5$ nicotinic acetylcholine receptor subunits in the chick brain. Brazilian J ournal of Medical and Biological Research, 30: 1209-1213.

16. Schoepfer R, Conroy WG, Whiting P, Gore $M \&$ Lindstrom J (1990). Brain $\alpha$-bungarotoxin binding protein cDNAs and mAbs reveal subtypes of this branch of the ligand-gated ion channel gene superfamily. Neuron, 5: 35-48.

17. Conroy WG, Vernallis $A B \&$ \& Berg $D K$ (1992). The $\alpha 5$ gene product assembles with multiple acetylcholine receptor subunits to form distinctive receptor subtypes in brain. Neuron, 9: 679-691.

18. Veenman CL \& Reiner A (1994). The distribution of GABA-containing perikarya, fibers, and terminals in the forebrain and midbrain of pigeons, with particular reference to the basal ganglia and its projection targets. J ournal of Comparative Neurology, 339: 209-250.

19. Alkondon M, Pereira EFR, Eisenberg HM \& Albuquerque EX (2000). Nicotinic receptor activation in human cerebral cortical interneurons: a mechanism for inhibition and disinhibition of neuronal networks. J ournal of Neuroscience, 20: 6675.

20. Hamassaki-Britto DE, Brzozowska-Prechtl A, Karten HJ , Lindstrom J M \& Keyser KT (1991). GABA-like immunoreactive cells containing nicotinic acetylcholine receptors in the chick retina. J ournal of Comparative Neurology, 313: 394-408. 